\title{
A comunicação não-verbal enquanto fator iatrogênico
}

\author{
NONVERBAL COMMUNICATION AS AN IATROGENIC FACTOR \\ LACOMUNICACIÓN NOVERBAL COMO FACTOR IATROGÉNICO

\section{Monica Martins Trovo de Araújo', Maria Júlia Paes da Silva², Ana Cláudia G. Puggina ${ }^{3}$}

\section{RESUMO}

O estudo teve como objetivo verificar se os enfermeiros identificam situações nas quais os aspectos não-verbais da comunicação interpessoal entre profissionais de saúde e pacientes constituem fator iatrogênico. Os dados foram coletados por meio de entrevista semi-estruturada com oito enfermeiros e analisados segundo a metodologia de análise de conteúdo. Do discurso dos profissionais emergiram três categorias, que evidenciam a percepção da iatrogenia, suas conseqüências e características e a interrelação entre a linguagem nãoverbal e o cuidado.

\section{DESCRITORES}

Comunicação não verbal. Relações interpessoais. Doença iatrogênica.

\begin{abstract}
The current study has the purpose of verifying if nurses are able to identify situations in which the nonverbal aspects of interpersonal communication between health professionals and patients constitute an iatrogenic factor. The data were collected through semistructured interviews with eight nurses and were analyzed according to the content analysis methodology. Three categories appeared from the professional discourses, and these categories make evident the perception of iatrogenesis, its consequences and characteristics and the interrelation between nonverbal language and nursing care.
\end{abstract}

\section{KEY WORDS}

Nonverbal communication. Interpersonal relations.

Iatrogenic disease.

\section{RESUMEN}

El estudio tuvo como objetivo chequear si las enfermeras identifican situaciones en las cuales los aspectos noverbales de la comunicación interpersonal entre los profesionales de la salud y los pacientes, constituyen factor iatrogénico. Los datos habían sido recogidos por medio de entrevistas mitad estructuradas con ocho enfermeras y analizadas de acuerdo con la metodología del análisis del contenido. Del discurso de los profesionales tres categorías habían emergido, que evidencian el factor iatrogénico, sus resultados y características y la interrelación entre la lengua noverbal y el cuidado.

\section{DESCRIPTORES}

Comunicación no verbal.

Relaciones interpersonales.

Enfermedad iatrogénica.
1 Enfermeira. Mestran da, Escola de Enfermagem da Universidade de São Paulo (EEUSP).Membro do Grupo de Pesquisa cadastrado no CNPq "Comunicação em Enfermagem”.São Paulo, SP, Brasil. monicatrovo@usp.br 2 Enfermeira. Professora Titular do Departamento de Enfermagem Médico-Cirúrgica da EEUSP. Membro do Grupo de Pesquisa cadastrado no CNPq "Comunicação em Enfermagem". São Paulo, SP, Brasil. juliaps@usp.br

3 Enfermeira. Mestranda da EEUSP. São Paulo, SP, Brasil. claudiapuggina@ hotmail.com 


\section{INTRODUÇÃO}

A comunicação é uma necessidade humana básica e, portanto, determina e efetua o atendimento da área expressiva de assistência ao paciente, sendo o denominador comum de todas as ações dos profissionais de saúde ${ }^{(1)}$. Independente de sua área de formação básica - enfermagem, fisioterapia, medicina, psicologia, entre outras - estes profissionais têm como base de seu trabalho as relações humanas ${ }^{(2)}$. Assim, é impossível ao enfermeiro cuidar, ao médico curar, ao fisioterapeuta reabilitar, ao psicólogo compreender e aconselhar ou qualquer outra ação na assistência ao ser humano sem lançar mão de habilidades de comunicação interpessoal.

Para a enfermagem, especificamente, a comunicação não é apenas mais um instrumento básico para o relacionamento terapêutico, mas deve ser considerada competência ou capacidade interpessoal. E essa competência é essencial para o enfermeiro, independente de sua área de atuação, pois permite atender as necessidades do paciente em todas as suas dimensões ${ }^{(1)}$.

Decodificar, decifrar e perceber o significado da mensagem que o paciente envia para estabelecer um plano de cuidados adequado às necessidades individuais do mesmo é tarefa dos profissionais de saúde ${ }^{(2)}$. Para que este processo complexo seja eficaz, não basta ao profissional utilizar somente a comunicação verbal; é preciso estar atento aos sinais nãoverbais emitidos durante a interação com o paciente.

A dimensão não-verbal da comunicação envolve todas as manifestações de comportamento não expressas por palavras, cuja significação está vinculada ao contexto em que ocorrem ${ }^{(1)}$. Os sinais não-verbais podem ser utilizados para complementar, substituir ou contradizer a comunicação verbal e também para demonstrar sentimentos ${ }^{(2)}$.

A comunicação não-verbal qualifica a interação humana, imprimindo emoções, sentimentos, adjetivos e um contexto que permite ao indivíduo perceber e compreender não apenas o que significam as palavras, mas também o que o emissor da mensagem sente. A qualificação da linguagem verbal é dada pelo tom de voz e jeito com que palavras são ditas, por olhares e expressões faciais, por gestos que acompanham o discurso, pela postura corporal, pelo tamanho da distância física que as pessoas mantém umas das outras e até mesmo por suas roupas, acessórios e características físicas. Mesmo o silêncio, em determinado contexto, é significativo e pode transmitir inúmeras mensagens.

A adequada interação entre a comunicação verbal e nãoverbal oferece maior qualidade ao relacionamento interpessoal e deve ser utilizada pelo enfermeiro e demais profissio- nais de saúde de forma mais consciente, servindo de instrumento gerador de um saber que pode contribuir para redescobrir e reconstruir a prática destes profissionais ${ }^{(3)}$.

No contexto da assistência à saúde do outro, toda comunicação verbal e não-verbal deve ser benéfica, efetiva, terapêutica. Conceitua-se a comunicação terapêutica como a habilidade do profissional em utilizar seu conhecimento sobre comunicação para ajudar a pessoa a enfrentar seus problemas, conviver com os outros, ajustar-se ao que não pode ser mudado e superar os bloqueios à auto-realização ${ }^{(1)}$.

Percebemos, contudo, que nem sempre a comunicação entre o profissional de saúde e o paciente é terapêutica. Há situações em que a interação para a expressão do eu para o outro recai sobre palavras, atitudes e mensagens mal construídas que podem ferir ou entorpecer o paciente, resultando em hostilidade contra o mensageiro, na exclusão do paciente de um compromisso terapêutico e comprometendo a formação do vínculo necessário ao processo de cuidar ${ }^{(4)}$. Deste modo, uma interação que deveria ser terapêutica pode ter efeito inverso e tornar-se iatrogênica.

Iatrogenia é uma palavra de origem grega que define o resultado indesejável pela ação prejudicial não intencional dos profissionais de saúde, relacionado à observação, monitorização ou intervenção terapêutica, caracterizando uma falha profissional por negligência $^{(5)}$. A imprudência do profissional relacionada à percepção inadequada ou má utilização da comunicação não-verbal na interação com o paciente pode caracterizar uma ocorrência iatrogênica à medida que traz sequielas psicológicas ao paciente, que podem ser mais cortantes que um afiado bisturi ou mais dolorosas que a dor física, influenciando de ma-neira decisiva o compromisso terapêutico e o curso do tratamento ${ }^{(4)}$.

A capacidade de julgamento do não-verbal enquanto instrumento terapêutico ou iatrogênico depende da percepção do profissional, ou seja, do processo de reconhecimento dos sinais pelos sentidos (visão, audição, gustação, tato e olfato) e interpretação dos mesmos pelo sistema nervoso. Como o processo de percepção ocorre em nível consciente, percebemos com mais facilidade o que é agradável, interessante ou possui significado especial para nós. Deste modo, mostra-se necessário que o profissional de saúde treine sua capacidade de percepção, uma vez que a rotina e os pequenos problemas do dia a dia faz com que o mesmo olhe sem ver, escute sem ouvir e toque sem sentir ${ }^{(2)}$.

Pesquisas mostram que os profissionais de saúde encontram dificuldades em perceber e utilizar os sinais nãoverbais de modo consciente. Existem estudos ${ }^{(6)}$ identificando que há falta de informações sobre comunicação entre os graduandos de medicina: embora os próprios estudantes a 
identificassem como importante para a compreensão do paciente e estabelecimento de vínculos, demonstraram não dominar os conceitos, pautando a relação interpessoal com o paciente muito mais em seu aspecto verbal do que nãoverbal.

$\mathrm{Na}$ enfermagem, estudos ${ }^{(7-10)}$ mostram que há falhas na percepção da comunicação não-verbal pelos enfermeiros em nível consciente, denotando necessidade de maior atenção e treinamento por parte destes profissionais.

Como a percepção dos sinais não-verbais ocorre em nível consciente, pode ser aperfeiçoada com esforço dirigido para seu aprendizado, treinamento e desenvolvimento ${ }^{(2)}$. Programas de treinamento em comunicação não-verbal têm sido desenvolvidos para enfermeiros hospitalares e estudantes de enfermagem ${ }^{(9,11-13)}$, envolvendo filmagens dos profissionais atuando, exposição teórica sobre comunicação não-verbal e relatos com exemplos da realidade vivida pelos profissionais em seu ambiente de trabalho.

O enfermeiro precisa refletir sobre a comunicação nãoverbal para torná-la mais consciente e ter recursos para entender seu próprio comportamento e o do paciente ${ }^{(14)}$. Assim, analisar criticamente a utilização da comunicação nãoverbal em sua prática diária oferece ao profissional a oportunidade de aprimoramento de sua percepção.

O interesse na realização deste estudo surgiu ao longo da disciplina de pós- graduação sobre comunicação nãoverbal da Escola de Enfermagem da USP, intitulada "Comunicação na Saúde do Adulto II - O não-verbal nas relações interpessoais", no ano de 2004. Durante as aulas, os colegas enfermeiros ilustravam os aspectos teóricos da comunicação não-verbal com exemplos reais da utilização terapêutica dos sinais não-verbais em sua prática diária de trabalho. Inúmeras situações vivenciadas foram relatadas, oferecendo a oportunidade de aprendizado baseado na reflexão crítica, enfocando a importância da percepção do profissional sobre o emprego terapêutico deste tipo de linguagem.

No entanto, poucos relatos denotavam que o mau uso da comunicação não-verbal poderia causar prejuízos aos pacientes. Surgiram então os questionamentos: Será que o enfermeiro, após adquirir ampla bagagem teórica sobre comunicação não-verbal, consegue perceber que sua utilização na interação entre profissionais de saúde e pacientes nem sempre é terapêutica? Será que ele identifica em sua vivência diária situações em que o não-verbal do profissional de saúde possa ter caracterizado uma ocorrência iatrogênica? É o que nos propomos a investigar.

\section{OBJETIVO}

Este estudo teve como objetivo verificar se os enfermeiros identificam situações nas quais os aspectos não-ver- bais da comunicação interpessoal entre profissionais de saúde e pacientes constituem fator iatrogênico.

\section{MÉTODO}

\section{Tipo de estudo}

Trata-se de um estudo descritivo, transversal, exploratório e de campo, com abordagem qualitativa, visto que o foco é complexo e a interpretação subjetiva, sendo o discurso o elemento básico de investigação.

\section{Local de estudo}

O estudo foi realizado na Escola de Enfermagem da Universidade de São Paulo.

\section{População}

Foram entrevistados oito alunos com vínculo na pósgraduação da universidade citada, matriculados e aprovados na disciplina de comunicação não-verbal, ministrada no primeiro semestre de 2004.

\section{Coleta de dados}

Após aprovação do Comitê de Ética em Pesquisa da instituição, em abril de 2005, houve tentativa de contato via e-mail com quinze enfermeiros que preenchiam os prérequisitos supra citados. Destes, dez manifestaram interesse em participar do estudo e foram agendados encontros individuais na Biblioteca da Escola de Enfermagem da USP, em dias e horários consensualmente acordados. Dois enfermeiros não compareceram ao encontro e não responderam às mensagens para tentativa de novo agendamento. Os dados foram coletados entre maio e outubro do mesmo ano, após aplicação do Termo de Consentimento Livre e Esclarecido, por meio de entrevista individual semiestruturada, com a seguinte questão norteadora: Você se lembra de alguma situação em que o não-verbal tenha sido iatrogênico para o paciente? Fale-me sobre ela. $\mathrm{O}$ discurso desses profissionais foi gravado em fita K-7 e posteriormente transcrito.

\section{Tratamento dos dados}

Os dados foram analisados segundo a metodologia da Análise de Conteúdo ${ }^{(15)}$, que propõe um conjunto de técnicas de análise da comunicação verbal, para obter indicadores, qualitativos ou não, que permitem a descrição do conteúdo das mensagens dos entrevistados. Seu método é composto de três fases (pré-análise, exploração do material e tratamento dos resultados, inferência e interpretação) e um dos critérios para a categorização dos dados pode ser o semântico ou temático, quando são agrupados todos os temas que têm o mesmo significado. 


\section{APRESENTAÇÃOE DISCUSSÃO DOS RESULTADOS}

Dos oito enfermeiros entrevistados, 4 (50\%) são docentes em cursos de graduação em enfermagem, 2 (25\%) associam docência à assistência a pacientes em hospital, 1(12,5\%) é enfermeiro assistencial exclusivamente e 1 (12,5\%) é administrador de uma unidade assistencial hospitalar. O tempo médio de formação das profissionais entrevistados é de 14,4 anos, com extremos de 3 e 26 anos.

Quando questionados a respeito do motivo pelo qual haviam se interessado por cursar a disciplina de pós-graduação Comunicação na Saúde do Adulto II - O não-verbal nas relações interpessoais, a maioria dos entrevistados citou mais de uma justificativa. O interesse pela disciplina por sua linha de pesquisa na pós-graduação ser comunicação interpessoal foi apontado $5(62,5 \%)$ vezes como justificativa; o interesse pessoal recebeu $5(62,5 \%)$ citações; o fato de ser a comunicação importante para a assistência que prestam foi relatado 2 (25\%) vezes e o interesse pela oportunidade de aprendizado foi apontado $1(12,5 \%)$ vez.

Dos oito enfermeiros participantes do estudo, destacase o fato de a maioria (75\%) ser docente em cursos de graduação em enfermagem e desenvolverem pesquisas direta ou indiretamente ligadas à comunicação não-verbal durante a pós-graduação. Chama atenção também o fato de que 7 $(87,5 \%)$ entrevistados optaram por estudar comunicação não-verbal durante a pós-graduação para aprimorar seus conhecimentos sobre o assunto, com vista não apenas às pesquisas que realizam, mas pela possibilidade de aperfeiçoamento do uso e percepção da linguagem não-verbal nos relacionamentos interpessoais em geral, seja com os pacientes, seja com os familiares, colegas de trabalho ou amigos.

Os entrevistados, cujo tempo médio de experiência profissional é relativamente longo, relataram dez situações em que a comunicação não-verbal foi por eles considerada iatrogênica para o paciente. Dos discursos destes profissionais emergiram três categorias, que evidenciam a percepção do comportamento iatrogênico, suas características e as implicações destas intercorrências para o cuidado de enfermagem.

\section{Percebendo a iatrogenia}

Ao discorrer sobre situações em que houve prejuízo ou desconforto do paciente devido à interação com profissionais de saúde, todos os enfermeiros entrevistados atribuem a responsabilidade pela conotação negativa da situação à inadequação do uso da comunicação não-verbal. Os discursos que se seguem exemplificam como e quanto a utilização inadequada de sinais não-verbais pode ser prejudicial:

Enfermeiro 1: ....a grande maioria das reclamações que eu respondo, são a mim direcionadas por comportamento da enfermagem; [...] as intercorrências que eu tenho com relação ao comportamento, elas são freqüentes e eu julgo sempre que é a postura sabe, como você chegou, o tom de voz que você usou, se você olhou para o paciente ou não. [...] O prejuízo é emocional para o paciente, que acaba ficando mais ansioso em relação ao que está acontecendo. Então o prejuízo mesmo eu acho que é de caráter emocional. E de imagem da instituição.

Enfermeiro 7: [...] uma aluna, que eu estava acompanhando em estágio e nós fomos fazer um curativo de uma paciente, era uma idosa que tinha feito fratura de cabeça de fêmur e colocou uma prótese. Tinha sutura e estava bastante edemaciado e avermelhado no local da sutura e nós íamos tirar os pontos. Aí, eu cheguei no quanto, levantei o lençol e quando expôs a ferida operatória, a aluna olhou para a ferida e fez uma cara de espanto tão grande, mas tão grande que a senhora disse: "Mas o que está acontecendo? Por que você está olhando desse jeito?". [...] Eu tentei minimizar, mas ficou muito evidente que ela ficou com medo da aluna. [...] O não-verbal dela falou tudo: falou o quão grave estava aquela cicatrização, que não estava "bonita", como a gente diz, e a paciente traduziu o não-verbal dela na hora.

Enfermeiro 5: [...] quando eu era enfermeira de centro cirúrgico [...] um dia veio uma moça procurar pelo pai. E procurando, encontrei que o pai tinha ido à óbito na noite anterior, tinha tido um AVC. Por coincidência, o neurocirurgião que o havia atendido estava de plantão. Então, eu achei que seria melhor se ele comunicasse a notícia, pois saberia responder melhor os detalhes. Pedi a ele que fosse conversar com a moça e ele foi. Lembro que havia uma porta de vidro separando a área limpa do CC da área contaminada. A moça ficou do lado sujo e ele do lado limpo, a uma certa distância dela. E ele começou a fazer uma série de perguntas: "O seu pai é aquele senhor que caiu do caminhão na semana passada?"; "É sim!";[...] "E ele ficou internado no pronto socorro desde o dia tal?"; "Sim, sim, é ele!"; "É, ele morreu". E virou as costas e foi embora. Ele simplesmente virou as costas e saiu! Eu achei aquilo tão horrível, tão agressivo! A moça fez uma cara de pavor, deu um grito e caiu sentada no chão, com um estrondo. [...] Por isso eu acho que a maneira como a gente se comunica pode ser iatrogênica para o paciente $e$ a família.

Enfermeiro 8: Uma vez, uma auxiliar de enfermagem foi realizar higiene íntima em uma paciente acamada, mas consciente, que havia evacuado. A expressão da auxiliar estava péssima, de descontentamento, nojo, causando grande constrangimento na paciente. Com isso, ela [paciente] se inibiu pra pedir ajuda para a higiene íntima, proporcionando o aparecimento de lesões, além do prejuízo psicológico, com a diminuição da auto-estima.

Nas quatro situações descritas ficam evidentes os sinais não-verbais que contribuíram para caracterizar a iatrogenia: postura corporal, tom de voz, distância pessoal, expressão facial, olhar. Conforme referido, estes e outros sinais nãoverbais podem ser utilizados para complementar, contradizer ou substituir a comunicação verbal na interação, porém, parece que a função contraditória merece maior destaque 
neste contexto. Não existe uma comunicação verbal iatrogênica, nos trechos descritos, mas claramente uma contradição entre o papel esperado do cuidador e sua ação.

Pesquisas mostram que os sinais não-verbais têm efeito cinco vezes maior que as palavras pronunciadas e quando não há coerência entre o que é falado e o que é percebido, as pessoas dão maior importância à mensagem não-verbal e desconsideram o que foi transmitido oralmente ${ }^{(14,16)}$. Deste modo, podemos inferir que mesmo que o profissional de saúde tenha um discurso verbal positivo e adequado com o paciente, seus sinais não-verbais é que determinarão o caráter terapêutico ou iatrogênico da interação, uma vez que são mais valorizados.

Algumas situações relatadas são identificadas pelos enfermeiros como prejudiciais aos pacientes pela associação do uso inadequado da linguagem verbal aos sinais nãoverbais, oferecendo à circunstância conotação negativa potencializada, ou seja, quando o discurso verbal inadequado é complementado por sinais não-verbais que reforçam o que está sendo dito. As falas seguintes ilustram este efeito:

Enfermeiro 2: [...] o médico falou: "Sr. Fulano, nós vamos colocar aquele outro 'canudo' aqui nesse tórax. Então, sem medo, nós vamos colocar uma anestesia e pronto". Tudo isso, em nomes técnicos. O doente não entendeu absolutamente nada e falou: "Peraí, de novo! Mas eu já fiz isso aí ontem e doeu muito...". O médico interrompeu: "Não, não, não. A gente não vai fazer isso com aquela agulhona, a gente vai fazer com aquele dreno maior".[...] Eles falam o verbal, de uma maneira muito ruim, que o paciente não alcança e no momento que estavam fazendo o procedimento, em nenhum momento olharam para o doente. Olhavam só o tórax e com aquele olhar de "não estou conseguindo, tá difícil”.

Enfermeiro 3: [...] tinha um garotinho que tava queimado, com queimaduras extensas, já numa fase mais adiantada, em que a ferida está infectada e tudo mais. [...] A auxiliar estava fazendo o curativo, a mãe do lado, nisso entrou o chefe médico do Pronto Socorro. Ele entrou e ele fez assim: "Schif, schif, schif [cheirando]. Nossa, que cheiro de carne podre! Como é que vocês agüentam esse cheiro de carne podre?". Virou e saiu. Aí, a mãe desabou a chorar, a auxiliar ficou totalmente revoltada e eu, mais ainda.

De acordo com os enfermeiros entrevistados, o prejuízo emocional que determinadas situações podem provocar depende da capacidade do paciente em perceber, contextualizar e julgar os sinais não-verbais. A percepção destes profissionais corrobora com o que diz a literatura ${ }^{(2,4,14,16)}$ : tanto o sentido conotativo quanto o denotativo da mensagem são dependentes da capacidade de percepção consciente da pessoa, no caso, o paciente. Os discursos seguintes denotam este fato:

Enfermeiro $4:[\ldots]$ é prejudicial no momento em que o paciente percebe, porque quando ele percebe, ele pode tanto se inibir, quanto causar uma situação de estresse, causar questionamentos, dúvidas com relação à assistência que ele está recebendo, se ele está recebendo todas as informações que deveria receber.

Enfermeiro 3: [No Pronto Socorro] Nós não temos boxes adequados, os pacientes ficam internados no corredor, em cadeiras, observando outras cenas acontecendo ao redor, o comentário dos internos, dos residentes e é muito complicado...

Esta última fala traz a tona o fato de que o paciente percebe e julga o não-verbal do profissional de saúde mesmo quando não está interagindo diretamente com o mesmo. Pesquisas mostram que 60 a $80 \%$ das pessoas formam sua opinião sobre recém chegados em menos de 4 minutos $^{(16)}$. Do mesmo modo, estudos apontam que interações que ocorrem "no corredor" provocam menor fidedignidade nas mensagens trocadas entre profissionais de saúde e pacientes ${ }^{(2)}$. Assim, as impressões geradas a partir da observação de cenas das quais o paciente não é participante podem ser extremamente negativas e interferir no posterior relacionamento interpessoal entre o paciente e o profissional que irá prestar-lhe assistência.

Outro aspecto destacado pelos entrevistados foi o fato de que o paciente que sofre este tipo de iatrogenia geralmente manifesta de modo não-verbal as conseqüências ou prejuízos da mesma, ou seja, ele oferece sinais não-verbais que denotam seu desconforto ou descontentamento frente à situação:

Enfermeiro 2: O doente ficou assim, extremamente pálido, com um olhar assustadíssimo e com muito medo.[...] Ele não reclamou em nenhum momento, mas ele tinha um olhar de muito medo. A gente percebe pelo olhar, por aquele olho arregalado, aquela sobrancelha pra cima, aquela cara de pavor. [...] A gente pode perceber pelo não-verbal do doente: a insatisfação, o medo, a ansiedade...

Pelo fato do feedback da iatrogenia não ser freqüentemente verbalizado pelo paciente, mas manifestado de modo não-verbal, o profissional pode não se dar conta do prejuízo causado. Assim, se o profissional não tem consciência da inadequação dos próprios sinais não-verbais emitidos, dificilmente conseguirá perceber e interpretar os sinais de ansiedade, descontentamento, medo, dúvida, incerteza causados por ele próprio e expressos pelo paciente durante a interação ${ }^{(12-13)}$.

\section{Caracterizando a iatrogenia}

A linguagem não-verbal é o reflexo do estado emocional da pessoa e, portanto, é subjetiva, assim como os sentimentos. Pelo fato da sociedade considerar alguns sentimentos negativos, o paciente não verbaliza sua tristeza, raiva, vergonha, medo, mas expressa de modo não-verbal e geralmente inconsciente, por meio de seu tom de voz, expressão facial, gestos, postura corporal ${ }^{(2,16)}$.

Uma vez que a expressão de sinais é uma ação muitas vezes inconsciente, não pode ser dissimulada pelo indivíduo. Assim, o profissional de saúde ao expressar sinais nãoverbais que são prejudiciais ao paciente, pode não perceber 
sua própria linguagem corporal inadequada ao seu discurso e ao seu fazer e, mesmo que perceba, não consegue controlála por todo o tempo. As falas dos enfermeiros entrevistados caracterizam a iatrogenia causada pelos profissionais de saúde como subjetiva, não-intencional e incontrolável, como nos trechos destacados:

\section{Enfermeiro 2: [...] eu não posso medir o quanto isso foi prejudicial.}

Enfermeiro 1: Você percebe que não houve má intenção, de causar um desconforto.

Enfermeiro 7: [...] E estava feio mesmo, estava feio demais, só que a aluna não conseguiu... O não-verbal dela falou tudo: falou o quão grave estava aquela cicatrização, que não estava "bonita", como a gente diz, e a paciente traduziu o não-verbal dela na hora.

Outra característica da iatrogenia destacada pelos enfermeiros foi a irreversibilidade de suas conseqüências, como denotam trechos de suas falas:

Enfermeiro 2: [...] a mãe não parava de chorar. Então nós conversamos com a mãe, mas o estrago já estava feito.

Enfermeiro 5: Eu corri, acudi, abanei, dei um copo de água, mas o estrago já havia sido feito.

Torna-se relevante à reflexão, a partir destes discursos, $\mathrm{o}$ caráter irreversível deste tipo de iatrogenia. No contexto do ambiente hospitalar, que por suas peculiaridades já favorece a insegurança do paciente, uma ação ou um sinal nãoverbal inadequados do profissional podem ser o "estopim" para situações de difícil resolução, tais como falta de confiança na equipe devido à um ato isolado de um profissional, falta de aderência ao tratamento, humor deprimido, agressividade dirigida aos profissionais, entre outras.

\section{Refletindo sobre comunicação não-verbal e cuidado}

Cuidar é um conceito amplo, subjetivo e que engloba várias ações. $\mathrm{Na}$ área da saúde e especificamente na enfermagem, cuidar significa, entre outras coisas, auxiliar ou mesmo realizar ações em favor da saúde e bem estar do outro. Neste contexto, o cuidado só é eficaz quando o ser cuidado - o paciente consente em ser alvo destas ações, cooperando e aderindo ao plano assistencial planejado pelo profissional.

Para permitir ser cuidado, o paciente precisa sentir-se seguro, confiar no profissional. Esse vínculo de confiança é dependente da comunicação interpessoal, uma vez que só confiamos em alguém quando percebemos coerência e constância entre o que ele diz e o que ele faz ${ }^{(14)}$. A fala do enfermeiro entrevistado, a seguir, denota que a má utilização dos sinais não-verbais impossibilita a formação do vínculo de confiança necessário ao cuidado:

Enfermeiro 7: [...] a paciente começou a analisar a cara feia da aluna, que estava horrorosa mesmo. Então eu comecei: "Não, não é bem assim, é que é o primeiro dia de estágio dela aqui...". Eu tentei minimizar, mas ficou muito evidente que ela ficou com medo da aluna. E quem acabou tirando os pontos fui eu! Foi uma judiação! E estava feio mesmo, estava feio demais, só que a aluna não conseguiu... O nãoverbal dela falou tudo: falou o quão grave estava aquela cicatrização, que não estava "bonita", como a gente diz, e a paciente traduziu o não-verbal dela na hora. Eu tentei minimizar, mas não deu certo, eu tive que assumir o cuidado. Não deu pra fazer o vínculo de confiança.

Do mesmo modo que identificam circunstâncias em que o comportamento não-verbal de profissionais de saúde foi iatrogênico ao paciente, os enfermeiros entrevistados relataram situações em que o uso adequado dos sinais nãoverbais tornou possível a formação do vínculo de confiança necessário ao cuidado, como no trecho que se segue:

Enfermeiro 3: Então eu toquei nela, segurei na mão dela bem forte e falei: "Dona Fulana, meu nome é $X$, e eu sou enfermeira, sou casada, tenho 2 filhos [...], eu sou enfermeira aqui desse centro cirúrgico e vou dizer uma coisa pra senhora: eu não tenho motivo para mentir pra senhora. Aquele lá é o seu médico. A senhora confia em mim?". Aí ela parou um pouquinho, olhou e falou: "Tá bom, eu vou confiar em você". Então ela relaxou e a cirurgia pode acontecer.

A comunicação terapêutica ${ }^{(1)}$ foi citada e valorizada em dois momentos distintos no discurso de um dos enfermeiros entrevistados enquanto instrumento necessário ao processo de cuidar, conforme denota sua fala:

Enfermeiro 2: [...] a menina [aluna] ficou o tempo todo junto. A gente não falou mais nada, naquele momento não se falou nada porque a gente já tinha dado toda a orientação. E só o fato de estar junto, a gente percebia que nessas horas ele [paciente] ficava um pouco mais tranqüilo.

Enfermeiro 2: Com um paciente consciente numa UTI, poucas vezes a gente vê o enfermeiro ir junto, nem que seja pra não falar nada, mas pra mostrar "estou aqui, do seu lado". A gente não vê isso! Segurar uma mão faz muita diferença.

Ao relatar as situações vivenciadas, alguns enfermeiros docentes também lembraram de situações nas quais o processo de ensino/aprendizagem sobre comunicação não-verbal ocorreu no campo prático, por meio de discussão e reflexão crítica sobre situações vivenciadas ou percebidas pelos alunos na interação com pacientes. Os trechos destacam estes relatos:

Enfermeiro 7: [...] nós saímos do quarto e eu falei com ela: "Fulana, você percebeu o que aconteceu?", "Claro, professora!". "O seu não-verbal fala mais do que 30 mil palavras!" eu falei pra ela. E a gente conversou muito disso. Eu sempre falava no grupo e esse foi um exemplo que a gente fez uma reflexão do não-verbal, porque eu sempre tento fazer, porque isso é evidente na nossa prática de enfermagem. Eu sempre trago para o grupo que aconteceu um evento assim e assado, sem citar o nome dela, mas falo que foi com uma aluna e ela não conseguiu cuidar e nem a paciente deixou ela cuidar. Isso é ótimo e eu uso até hoje como exemplo da importância do não-verbal. 
Enfermeiro 2: [...] foi muito interessante porque o aluno quando vê essas coisas... Porque a gente fala, mas quando ele vê, a coisa fica mais clara pra ele. [...] Depois as meninas comentaram bastante sobre isso, nós pudemos discutir bastante sobre isso, o que foi muito legal pras meninas aprenderem o quanto é importante o estar junto. $E$ o quanto a gente acaba não se preocupando.

Percebemos pelos discursos citados que os enfermeiros que aperfeiçoam seus conhecimentos sobre comunicação não-verbal utilizam a reflexão crítica baseada na experiência prática de situações vivenciadas, não apenas para o aprimoramento de suas ações, mas também como ferramenta na supervisão e ensino de alunos de graduação, possibilitando a formação de enfermeiros mais conscientes de seu próprio processo de comunicação e da inter-relação deste com o cuidado que irão prestar.

\section{CONSIDERAÇÕES FINAIS}

Os enfermeiros participantes do estudo foram capazes de identificar situações em seu cotidiano de trabalho nas quais os sinais não-verbais da interação entre profissionais de saúde e pacientes constituíram fator iatrogênico. Além

\section{REFERÊNCIAS}

1. Stefanelli MC. Comunicação com o paciente: teoria e ensino. São Paulo: Robe; 1993.

2. Silva MJP. Comunicação tem remédio: a comunicação nas relações interpessoais em saúde. São Paulo: Loyola; 2002.

3. Lisboa MAPLP. Comunicação não-verbal na entrevista de avaliação de desempenho. In: Anais do $2^{\circ}$ Encontro Internacional de Pesquisa em Enfermagem; 2002; Águas de Lindóia. Águas de Lindóia: Escola de Enfermagem, Universidade de São Paulo; 2002. p. 43.

4. Pericardis AAM. Comunicação iatrogênica na cancerologia. Rev Soc Bras Cancerol. 1999; 2(8):11-3.

5. Padilha KG. A prática de enfermagem em UTI e as ocorrências iatrogênicas: considerações sobre o contexto atual. Rev Paul Enferm. 2000;19(3):49-56.

6. Moneia ACL. A importância e a compreensão verbal e nãoverbal sob a ótica do graduando de medicina [dissertação]. São Paulo: Escola de Enfermagem, Universidade de São Paulo; 2002.

7. Carvalho DV. Necessidade territorial do paciente hospitalizado [tese]. São Paulo: Escola de Enfermagem, Universidade de São Paulo; 1987.

8. Sawada ND. A dimensão não-verbal da interação enfermeiropaciente em situação pré-operatória [dissertação]. Ribeirão Preto: Escola de Enfermagem de Ribeirão Preto, Universidade de São Paulo; 1990. de identificar e relatar situações, caracterizaram a iatrogenia enquanto comportamento subjetivo, não-intencional, incontrolável e cujas conseqüências/prejuízos são emocionais e irreversíveis.

Ao relatar situações iatrogênicas, também refletiram, lembraram e valorizaram situações nas quais a comunicação foi terapêutica, relacionando-as com a eficácia do cuidado prestado e exemplificaram o modo como o processo de ensino/ aprendizagem relativo aos sinais não-verbais na interação com pacientes pode ocorrer por meio da reflexão crítica baseada na prática diária. Com isso, o não-verbal pode ser mais consciente e adequado.

A excessiva atenção dada à comunicação verbal faz com que sejamos profundamente desinformados a respeito da linguagem não-verbal e da importância que ela tem em nossos relacionamentos, sejam pessoais ou profissionais. Este estudo, apesar de sua limitação relativa à pequena amostra de profissionais, pode demonstrar que os enfermeiros buscam aprimorar seus conhecimentos relativos à comunicação não-verbal para evitar que um cuidado planejado para ser terapêutico se transforme em uma iatrogenia.

9. Silva MJP. A percepção da enfermeira sobre a comunicação nãoverbal dos pacientes [dissertação]. São Paulo: Escola de Enfermagem, Universidade de São Paulo; 1989.

10. Bertoncello KCG. Comunicação não-verbal do paciente em CTI coronariana submetido a intubação orotraqueal [dissertação]. Ribeirão Preto: Escola de Enfermagem de Ribeirão Preto, Universidade de São Paulo; 1999.

11. Silva MJP. Construção e validação de um programa sobre comunicação não-verbal para enfermeiros [tese]. São Paulo: Escola de Enfermagem, Universidade de São Paulo; 1993.

12. Silva MJP. Analisis comparativo de lãs aplicaciones de programa sobre comunicación no verbal para enfermeras hospitalares. In: Anais do $8^{\circ}$ Congresso de La Sociedad Cubana de Enfermería; 1998; Santiago de Cuba. Santiago de Cuba: Sociedad Cubana de Enfermería; 1998. p. 128.

13. Castro RCBR. Estimulando a enfermeira de saúde mental a perceber sua própria comunicação não-verbal. In: Anais do $9^{\circ}$ Simpósio Brasileiro de Comunicação em Enfermagem; 2004; Ribeirão Preto. Ribeirão Preto: Escola de Enfermagem de Ribeirão Preto, Universidade de São Paulo; 2004. p. 45.

14. Silva MJP. Percebendo o ser humano além da doença: o nãoverbal detectado pelo enfermeiro. Nursing (São Paulo). 2001;4(41):14-20.

15. Bardin L. Análise de conteúdo. Lisboa: Edições 70; 1977.

16. Pease A, Pease B. Desvendando os segredos da linguagem corporal. Rio de Janeiro: Sextante; 2005. 